\title{
A New Prototype Design and Experimental Study for Assessing Spontaneous Coal Combustion
}

\author{
Aryansyah ${ }^{1,4^{*}}$, Eddy Ibrahim ${ }^{2}$, Subriyer Nasir ${ }^{3}$, \\ Muhammad Said ${ }^{3}$, lan Kurniawan ${ }^{5}$, Adri Huda' \\ 1 Department of Environmental Sciences, Sriwijaya University, Palembang, Indonesia \\ 2 Mining Engineering Study Program, Faculty of Engineering, Sriwijaya University, Palembang, Indonesia \\ ${ }^{3}$ Chemical Engineering Study Program, Faculty of Engineering, Sriwijaya University, Palembang, Indonesia \\ ${ }^{4}$ Department of Energy and Mineral Resources of the Provincial Government of South Sumatra, Palembang, \\ Indonesia \\ ${ }^{5}$ Department of Medic Laboratory Technology, Musi Charitas Catholic University, Palembang, Indonesia \\ * Corresponding author's e-mail: arik120677@gmail.com
}

\begin{abstract}
This present study contribute to provide a simple technology to early detect the phenomenon of spontaneous coal combustion. A new prototype is designated to detect the $\mathrm{CO}$ gas formation as a product of initial coal oxidation. Moreover, several parameters including coal quality, coal weight sample, ambient temperature, and air flow were employed to investigate the effects of each parameter to the $\mathrm{CO}$ formation time. The results show that the coal characterisation have a significant effect in the $\mathrm{CO}$ formation time where the coal having a higher fixed carbon and high grass calorific values provide the high liability of spontaneous coal combustion. However, these finding only occurred in low weight sample where in the high coal weight sample only fixed carbon plays the main role in determining the $\mathrm{CO}$ formation time. Furthermore, the prototype ambient temperature become the important parameter in the boosting of $\mathrm{CO}$ formation time where airflow only enhance the $\mathrm{CO}$ formation time in low temperature condition (below $29^{\circ} \mathrm{C}$ ). Moreover, these findings opens a new sight in coal management, especially in Indonesia, where controlling the coal and atmosphere temperature could effectively prevent the spontaneous coal combustion especially in coal stockpile. Nevertheless, the other factor including airflow and coal weight sample also need perfect controlling because all of these factors potentially create a perfect environment to combust the coal spontaneously.
\end{abstract}

Keywords: coal, spontaneous combustion, energy management, environmental technology, oxidation

\section{INTRODUCTION}

The environmental degradation become the international attention in last several decades because it determines the sustainability of humanlife and other biotics and abiotics things. The degradation occurs because of the decreasing of environmental supports. The decreasing of environmental support is generated by anthropogenic activities which potentially pollute water (Kurniawan, 2017 and Huda, 2019), soil (Artiola, 2019), and air (Mcneill, 2019). To be more specific in air pollution, spontaneous coal combustion contribute as one of air pollution source in Indonesia because it can generate several greenhouse gases such as carbon dioxide $\left(\mathrm{CO}_{2}\right)$, methane $\left(\mathrm{CH}_{4}\right)$, etc. However, the study about the contribution of spontaneous coal combustion to supply the pollution to the atmosphere still become the challenges.

Spontaneous Coal Combustion (SCC) is a phenomenon of coal combustion initiated by selfheating on the coal surface without any additional external heating. The SCC commonly occurs in the coal mining, coal stockpile and coal transit without any warning. Thus, the presence of SCC in the coal mining provides the high risk to the mining worker and mining environment due to the potential initiating the fire. Several countries such as Indonesia, United States, China, India, South Africa, Germany, etc, have reported the 
seriously disastrous spontaneous coal combustion events (Kuenzer, 2012). Moreover, it is important to maintain and prevent the SCC before occurred and become the problem. Beside, the presence of SCC is not efficient in economical aspect due to ineffective utilization of coal which should be converted as energy. Thus, natural coal combustion through SCC means wasting the energy and definitely losing money.

In basic mechanism, SCC is initiated by selfheating generated by chemical oxidation process in the coal surface initiated by oxygen content in the atmosphere. The SCC can occur because coal is an organic matters in the form of reactive porous media which easily oxidized through the oxidation reaction. However, because of the organic combustion, the SCC potentially generates the significant pollutant such as the greenhouse gases as well carbon dioxide and methane. However, due to the lack of information and no recognised method for making reliable estimates, the contribution of SPC in the climate change inventory was not made (United States of Environmental Protection Agency, 2018). Heffern and Coates (2004) reported that the amount of coal lost due to natural coal combustion including SCC is one or two times greater than the amount of coal used in the last century. Similar to Heffern and Coates, O'Keefe (2010) reported that the amount of global coal combustion in coal seam and coal waste is $0.5 \%$ to $10 \%$ of global annual production. Further, it still become the interesting issues especially in economic and environmental sights to estimate the number of emission generated by SCC using the theoretical or experimental study.

Besides, it also becomes the challenge to determine the effective ways to prevent the SCC. Several studies have been conducted to model and determine the SCC (Wu, et. al., 2019; Wang and Chen, 2015; and O'Keefe, 2010). However, these obtained emission are not representative of total GHG emission in the real coal mining, stockpile, or coal transit area. these previous experiment have only focused on how the SCC formed and did not detected the early formation of GHG, indicating the SCC initiation. Therefore, our present work is focused on design the tool or prototype to estimate the early formation of GHG through SPC phenomenon. We thought that the early formation can be detected by measuring carbon monoxide (CO) formation. The study about detecting early formation of coal oxidation can help to reduce the number of coal wasted as greenhouse and also prevent the accidents generated by coal fires. Furthermore, the study used several parameters which potentially affect the SCC such as the coal quality, coal weight, ambient temperature, and air flow concentration. The effects of each parameter will be experimentally investigated. The result is expected becoming a reference to prevent the early formation of SCC in the coal mining activity, especially preventing SCC in coal stockpile. Concurrently. the obtained result also can be used to strategize the further action to prevent the SCC.

\section{EXPERIMENTAL}

\section{Sample collection and preparation}

The coal sample used in this present experiment was taken from the commercial coal mining of PT. Bukit Asam, Tbk which is located in South Sumatera, Indonesia and kept in airtight bag to avoid the coal oxidation. In order to make the representative sample, the obtained sample was taken from several selected coal bands of coal seam, coal highhill, and stockpile which have been separated based on coal calorific qualities. Further, all the collected coal is mixed to form the composite samples. However, before analyzing the coal physicochemical properties, the fresh coal sample is crushed using a mortar and pestle to form the homogenous particle size and kept in airtight bag. The coal particle size is not further analyzed and limited by the weight for each analysis and tests.

\section{Analysis of coal characterization}

There are three types of coal collected and prepared in this study which is 4800 calorific coal, 5000 calorific coal, and 6500 calorific coal. The types of coal are classified by PT. Bukit Asam, Tbk. as the company which manage and purchase these coal. However, the coal analysis should be double checked to definite the coal sample characterisation. Therefore, the characterisation tests including the content test of moisture, ash, volatile matter, fixed carbon and gross calorific value analysis are carefully conducted. As a reference, American Society of Testing and Materials (ASTM) standards and International Standardisation Organisation (ISO) are used as the standard of analysis procedures for each characterisation parameter. 


\section{Design of experimental study}

As mentioned above, the basic idea study of spontaneous coal combustion is done by investigating the generation of carbon monoxide as the early product of coal oxidation. To be more specific, the investigation is carried out by counting the formation time of $1 \mathrm{~g} / \mathrm{L}$ (ppm) of carbon monoxide during the coal oxidation experiment. All the experiment is carried out in laboratory scale under the spontaneous coal combustion prototype (SCCP) developed by Environmental Science Department of Universitas Sriwijaya, Indonesia (Figure 1). In addition, there are several parameters which kept constant during the coal oxidation which are oxygen concentration (20.9 ppm) and moisture contents $(65-75 \%)$. The numbers of oxygen and moisture levels are obtained from the preliminary analysis which shown that these condition provide the minimum condition to see the spontaneous coal combustion in our developedprototype. Furthermore, these conditions aim to provide the similar approach to the real time condition in coal stockpile.

The experiment began with flowing $5 \mathrm{sccm}$ of airflow into the coal heat oven (1) for 30 minutes to sterilize the prototype from the ambient gases. During the coal oxidation, the oven temperature is kept at $25^{\circ} \mathrm{C}$ and carefully controlled using a thermocouple. After 30 minutes, 250 grams of coal sample are put onto the center of coal heat oven (1) which used as the coal oxidation zone. Further, $1 \mathrm{sccm}$ of airflow is continuously injected into the coal oxidation zone and controlled in control panel system. When the airflow valve is opened, a timer is set to count the time of coal oxidation. Simultaneously, a gas analyzer started to analyze the produced-gas which released from the oven centre (2). After $1 \mathrm{ppm}$ of $\mathrm{CO}$ gas formed during the coal oxidation, the timer is stopped and the times are calculated as the $\mathrm{CO}$ formation time.

In order to see the effect of coal quality to the $\mathrm{CO}$ formation time, three types of coal are used and put as the coal sample. After investigating the effect of coal quality to $\mathrm{CO}$ formation time, the study is continued by investigating the coal weight to $\mathrm{CO}$ formation time. Four level of coal weight which began from 250 grams, 500 grams, 750 grams, and 1000 grams are used to investigate the effect of coal weight to $\mathrm{CO}$ formation time. After investigating the effect of coal weight sample, the study is continued by investigating the temperature effect to $\mathrm{CO}$ formation time by changing the ambient temperature to five levels began from $25^{\circ} \mathrm{C}, 27^{\circ} \mathrm{C}, 29^{\circ} \mathrm{C}, 31^{\circ} \mathrm{C}$ and $33^{\circ} \mathrm{C}$. Moreover, In order to see if temperature provide the effect in each coal weight sample, the study of temperature effect is also conducted in four levels of coal weight sample. Finally, the present study is conducted by investigate the effects of airflow to the $\mathrm{CO}$ formation time which is done by varying the injected airflow to coal oxidation zone using five levels of airflow levels started at $1 \mathrm{sccm}$ to 5 $\mathrm{sccm}$. As a consequence, every single experiment is done by following the similar procedure with the previous experiment and only change some parameters which affect the $\mathrm{CO}$ formation time.

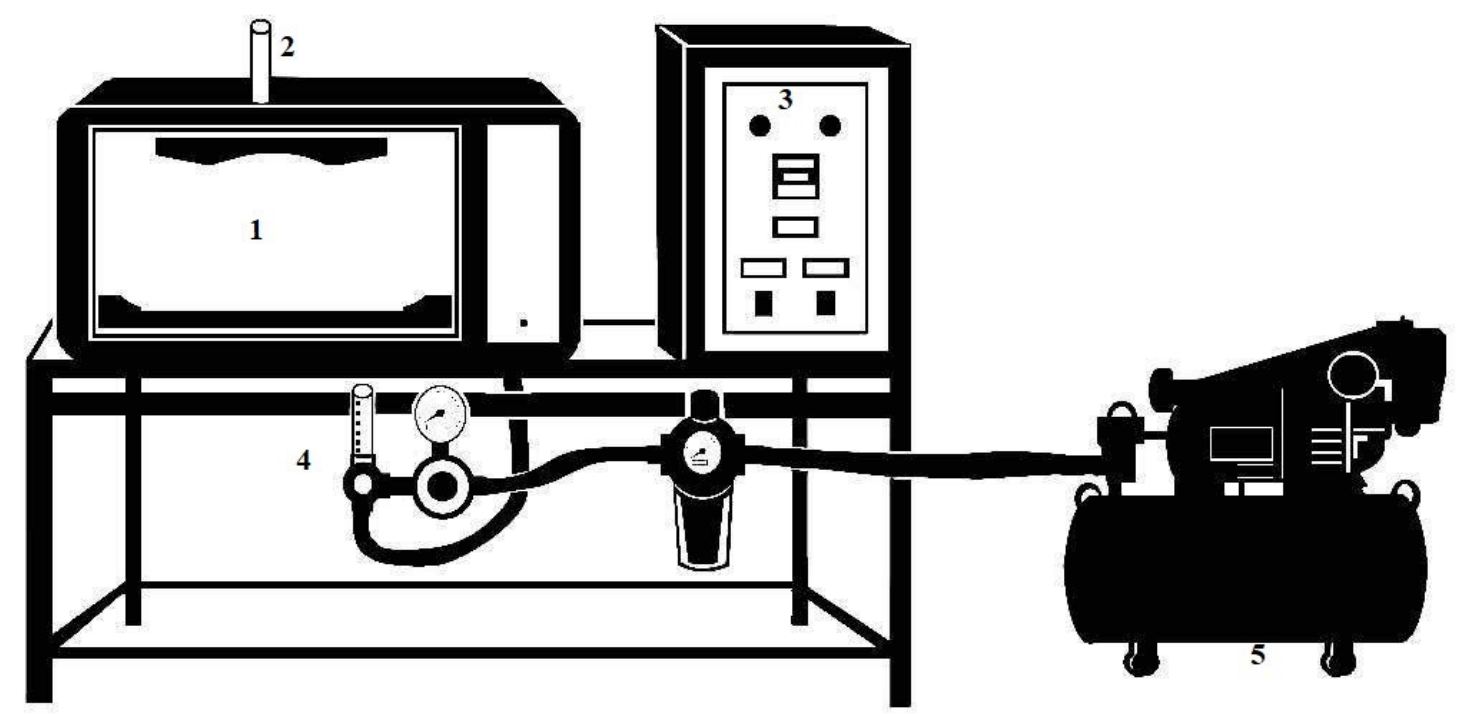

Figure 1. Design of spontaneous coal combustion prototype measurement: 1 - coal heat oven (stockpile model), 2 - line to gas analyzer, 3 - control panel, 4 - air flow control, 5 - compressor 


\section{RESULT AND DISCUSSION}

The study of spontaneous coal combustion is conducted by measuring the early formation of carbon monoxide in the developed coal stockpile prototype. The basic idea is based on our perspective that the spontaneous coal combustion began by simply oxidizing the coal as the main material. Further, the coal is a material which mined from a high pressure underground layer which consisted of soil and rock. However, when the coal is mined, the coal is expanding due to air pressure coming from atmosphere to the inner of coal material. This phenomenon provide two process which is physical process (adsorption) and physicochemical process (adsorption and chemical oxidation). The physical process only absorb and release the air flowing to the coal materials. However, physicochemical proves involves the chemical oxidation which potentially initiate the reaction on the coal seam, resulting in heat as the byproduct. This phenomenon is well known as self-heating phenomenon which basically mean the heating of coal through the coal oxidation. The continuously coal oxidation generated by air adsorption in the coal surface is further regarded to spontaneous coal combustion (Wang, 2018). Pone (2007) tried to figure out the basic reaction of spontaneous coal combustion through coal oxidation which shown below.

$$
\text { Coal }+ \text { Oxygen } \rightarrow \text { Oxycoal }+ \text { Heat } \rightarrow \text { Gas }
$$

As we can see in the equation 1 , the spontaneous coal combustion is a product of coal oxidation which consist of organic compounds. The gas released during the spontaneous coal combustion is a product of oxidized-based organic compound. According to basic knowledge about organic oxidation, the combustion of organic compound by oxygen will generate carbon monoxide as the incomplete oxidation combustion and carbon dioxide as the product of complete oxidation combustion (Huda, 2019). Based on above statement, we beliefs that the early formation of spontaneous coal combustion began by forming carbon monoxide as the product of coal oxidation. Thus, this present study is focused on investigating the early formation of carbon monoxide as a function of several parameters which potentially affect and initiate spontaneous coal combustion.

In this study, the obtained coal samples are sampled in PT. Bukit Asam, Tbk as one of the oldest coal mining in Indonesia. There are three samples used in this study including 4800, 5000, and 6500 calories coal samples. The coal calories differentiate the coal type in which 6500 calories sample is the highest quality of coal sample. Moreover, all the three types of coal sample is used to investigate the phenomenon of spontaneous coal combustion. It is based on facts that the spontaneous coal combustion (SCC) occurred in those three coal sample mining, stockpile, and transfer. Thus, the result study provides the new information about the phenomenon of SCC which will be used in the further coal management techniques.

\section{The effect of coal quality}

Figure 2 shows $\mathrm{CO}$ formation time as the function of coal qualities. The results show the coal quality differentiate $\mathrm{CO}$ formation time. It can be seen the coal sample of 4800 calories and 6500 coal calories present the latest CO formation, while the coal sample of 5000 calories has the fast $\mathrm{CO}$ formation. In order to investigate the correlation between the coal quality and $\mathrm{CO}$ formation time, several analysis have been conducted. and the result is shown in Table 1.

Table 1 confirm that the $\mathrm{CO}$ formation time is affected by the coal quality. To be more specific, it can be seen that the sample of 5000 calories has the lowest number of moisture compared to the one higher quality. Based on literature studies, the moisture can affect the coal oxidation through releasing the latent heat of vaporization and positively correlate to the formation time of $\mathrm{CO}$ gas. In basic mechanism of coal oxidation, it began by dissolving oxygen which used to oxidize the coal to water content and continued by moving to

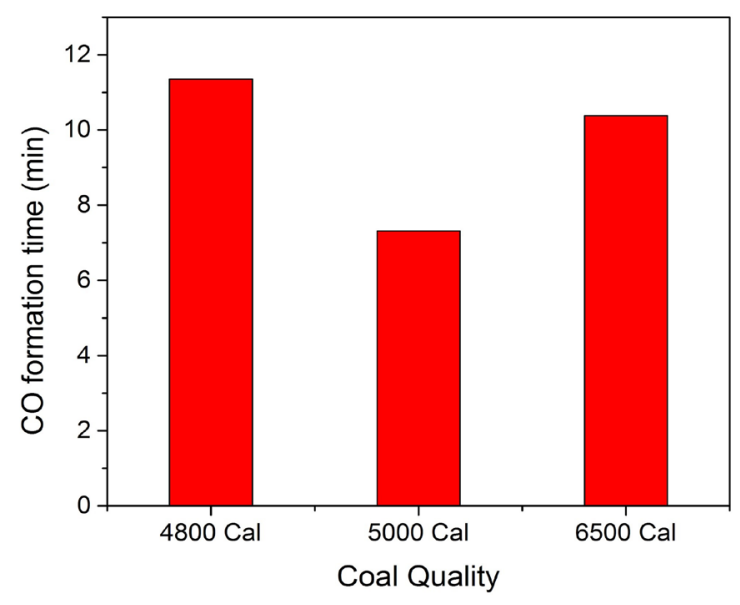

Figure 2. CO formation time as a function of coal quality 
Table 1. The result of coal characterization test

\begin{tabular}{|c|l|c|c|c|c|}
\hline \multirow{2}{*}{ No } & \multirow{2}{*}{ Parameter } & \multirow{2}{*}{ Standard method } & \multicolumn{3}{|c|}{ Coal quality } \\
\cline { 4 - 5 } & & & Low & Middle & High \\
\hline 1 & Moisture & ASTM D.3173-11 & 9.13 & 3.20 & 4.99 \\
\hline 2 & Ash & ASTM D.3174-11 & 10.41 & 8.26 & 6.90 \\
\hline 3 & Volatile matter & ISO-562:2010 (E) & 39.04 & 38.10 & 37.18 \\
\hline 4 & Fixed carbon & ASTM 3172-02 (11) & 41.42 & 50.44 & 50.93 \\
\hline 5 & Gross calorific value & ASTM D.5865 & 5.727 & 7.104 & 6.856 \\
\hline
\end{tabular}

the active site in the coal surface. The presence of oxygen in the coal surface or/and contains in the coal composition raises the temperature of coal and increase the rate of oxidation in the coal dry region (Bhat and Agarwal, 1996). However, the present result shows the opposite phenomenon with the literatures, it can be seen that the sample which has the lowest moisture has the fastest $\mathrm{CO}$ gas formation, while the high moisture coal sample have slower $\mathrm{CO}$ formation. The result is in line with the reported work conducted by Onifade and Genc (2018) where the lower moisture of coal sample provides high liability to spontaneous coal combustion. This phenomenon have become the interesting issue about how can moisture affect the phenomenon of spontaneous coal combustion. Beamish and Schultz (2008) reported that there were an optimum moisture content which could enhance the initial rate of coal self-heating. On the other hand, Beamish and Hamilton (2005) found that the optimum self-heating can be reached after the coal had lost half of its moisture holding capacity. However, all the used sample have the relative low moisture sample (below 10\%) which is categorized as the high rank coal quality (ASTM, 2004). Thus, the effect of moisture to determine the $\mathrm{CO}$ formation time can be discrepancies noted. This is in line with Stracher (2015) which reported that moisture can fully affect the spontaneous coal combustion in high moisture coal, or dried or partially dried low rank coal quality.

he effect of $\mathrm{CO}$ formation time can also be affected by the volatile matters (Banerjee, 2000). However, all the three samples have relatively similar of volatile matters, thus this parameter do not affect that much to $\mathrm{CO}$ formation time. Furthermore, the contained number of fix carbon and gross calorific values opens the discussion. It can be seen that the coal sample which has a higher fixed carbon and high grass calorific values has the high liability of spontaneous coal combustion. It is in accordance with the classification of coal where the fixed carbon and gross calorific values can determine the quality of coal sample. In term of coal oxidation, the high fixed carbon provides the wide porous active medium which provide the self-heating, resulting in high or fast spontaneous combustion (Onifade and Genc, 2018). Furthermore, the result of gross calorific value analysis shows that the coal sample of 5000 has higher carbon surfaces or contents compared to the other sample. Thus, those sample has the fastest $\mathrm{CO}$ formation compared to the other sample.

\section{The effect of coal weight}

The study was continued by investigating the effect of coal weight sample in the $\mathrm{CO}$ formation time. It can be seen that the shorter $\mathrm{CO}$ formation time is formed when the weight of coal sample is increased. There is a positive correlation between the weight of coal sample and the CO formation time. It is because of the higher weight of coal sample provides the higher coal surface which can be oxidized. However, Figure 3 shows that there is a slightly increase of $\mathrm{CO}$ formation time at the coal weight sample of $1000 \mathrm{~g}$ (maximum capacity of our spontaneous coal combustion prototype) in the coal sample of 4800 calories meaning that the higher weight coal sample in a stockpile provides the higher potential of spontaneous coal combustion. It is also happened in the other coal qualities (5000 calories and 6500 calories). However, there is no comprehensive study about the effect of coal weight and the height of coal pile in term of spontaneous coal combustion in this present study, meaning these parameter effect could be negligible.

To be more specific in the result of $\mathrm{CO}$ formation time in the coal sample of 6500 calories, the $\mathrm{CO}$ formation time in $1000 \mathrm{~g}$ sample is higher than 500 gram and 750 gram due to the number of $\mathrm{CO}$ is not $1 \mathrm{ppm}$ (which mostly detected in the other experiment) but $3 \mathrm{ppm}$. The $\mathrm{CO}$ formation 


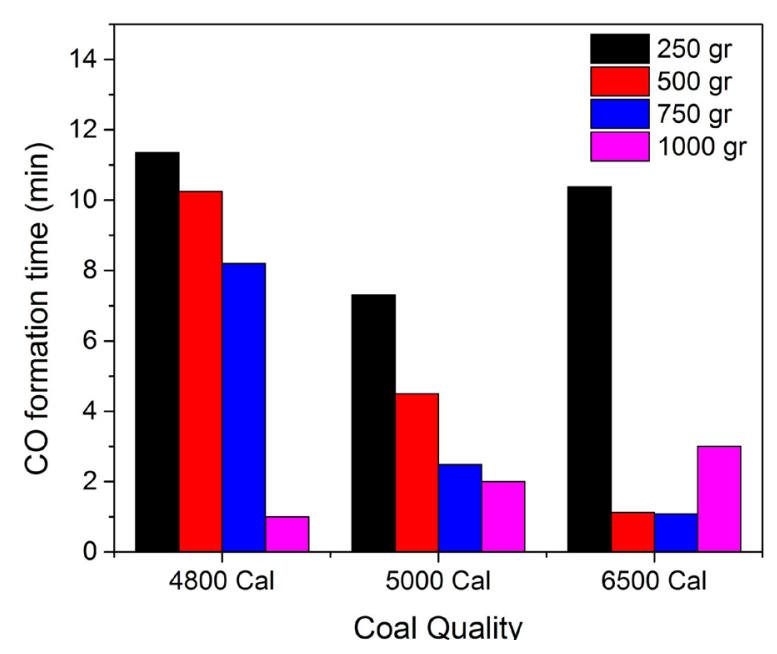

Figure 3. The effect of coal weight in $\mathrm{CO}$ formation time

time in 1000 gram of 6500 coal sample should be the fastest compared to the other experiment condition. Furthermore, the $\mathrm{CO}$ formation time of coal sample of 4800 and 6500 calories show a faster formation time compared to that one from 5000 calories coal sample, indicating that the coal weight sample affect the $\mathrm{CO}$ formation time. In addition, the 6500 calories coal sample provides the fastest $\mathrm{CO}$ formation in the coal weight sample of $500 \mathrm{~g}, 750 \mathrm{~g}$, and $1000 \mathrm{~g}$ of sample due to the high number of fixed carbon of 6500 calories coal sample compared to the other coal sample. In term of 1000 grams, there is a interesting result that the coal weight sample dominate the $\mathrm{CO}$ formation time than the coal quality. However, these findings need to be confirmed in the next step of experiment to see the effect of coal weight in $\mathrm{CO}$ formation time.

\section{The effect of temperature on the CO formation time}

The study of effect on the $\mathrm{CO}$ formation time aims to give an approach to the prototype to the real condition of coal mining and stockpile. There are five levels of temperatures used in this experiment determined by the common ambient temperature in coal mining and stockpile in Indonesia. Figure 4 shows that the increasing of ambient temperature boost the $\mathrm{CO}$ formation time. The temperature provides an additional energy to oxygen to oxidize the coal surface, leading fast $\mathrm{CO}$ formation time. Stracher (2015) explain the correlation between the correlation of temperature to coal oxidation as shown in equation 2 .

$$
R_{o}=A e^{-E / R T}
$$

where: A refers to the factor of pre-exponential which is related to the frequency of oxygen contact the coal active media).

$E$ is the energy activation, $R$ is the gas constant, and

$T$ is the reaction temperature.

Figure 4(A) indicates that the CO formation time of the 4800 has slightly improvement in $\mathrm{CO}$ formation time after the temperature reached $29^{\circ} \mathrm{C}$. This approach has also conducted in the 5000 calories coal sample. Moreover, the 6500 calories coal sample has the improvement since the temperature reached $27^{\circ} \mathrm{C}$. However, the 5000 calories coal sample still has the fastest $\mathrm{CO}$ formation time compared to the other coal sample in every given-ambient temperature.

After obtaining the effect of temperature to $\mathrm{CO}$ formation time, the study was continued by comparing the trends of $\mathrm{CO}$ formation as a function of coal sample weight. This study is used to confirm the effect of coal weight sample in $\mathrm{CO}$ formation time and combine its effect to the temperature function. At 500 gram of coal sample. it can be seen that the trend of $\mathrm{CO}$ formation time is different with the 250 gram sample where 6500 calories coal sample provide the fastest $\mathrm{CO}$ formation time in every temperature. This pathways is also occurred in the 750 gram and 1000 gram of coal samples. In detail, the 4800 coal sample has the slowly improvement of $\mathrm{CO}$ formation when the temperature enhanced, especially at the coal weight of $750 \mathrm{~g}$. Moreover, at the high calories sample (5000 and 6500 calories), the CO formation time is slightly improved by enhancing the coal temperature. It is because the high number of coal weight will produce high number of $\mathrm{CO}$, resulting in faster $\mathrm{CO}$ formation time compared to $250 \mathrm{~g}$ of coal sample. However, the $6500 \mathrm{coal}$ sample provides the fastest $\mathrm{CO}$ formation time in every single temperature at $500 \mathrm{~g}, 750 \mathrm{~g}$, and $1000 \mathrm{~g}$ of coal weight sample due to providing high fixed carbon content. It can be concluded that in the higher coal weight sample, the number of fixed carbon played the role in determining of $\mathrm{CO}$ formation time than the combination of number of fixed carbon and high grass calorific values which determine the $\mathrm{CO}$ formation time in 250 gram of sample. Moreover, we found that the temperature and coal sample weight sample provide the significant effect to the low calories coal compared to the higher calories coal. 
(A)

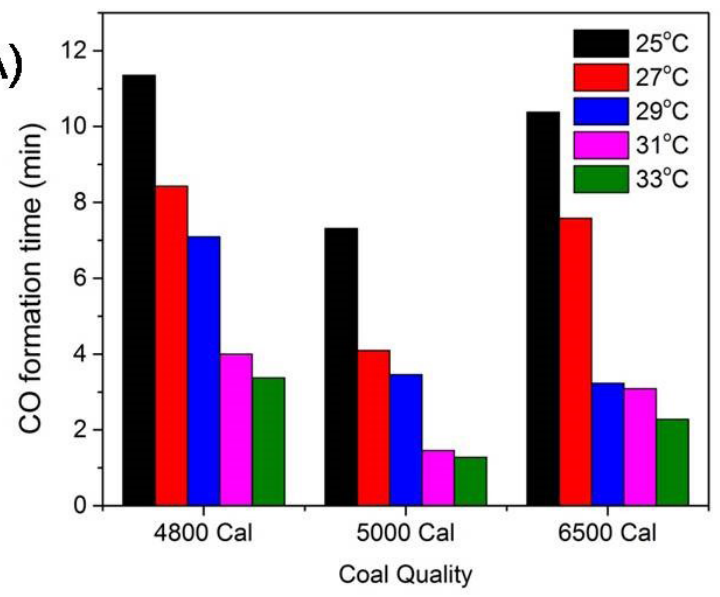

(C)

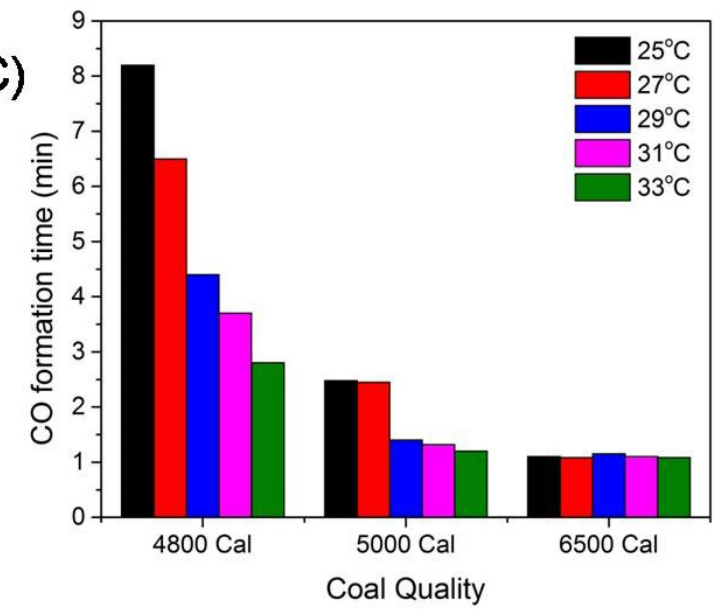

(B)
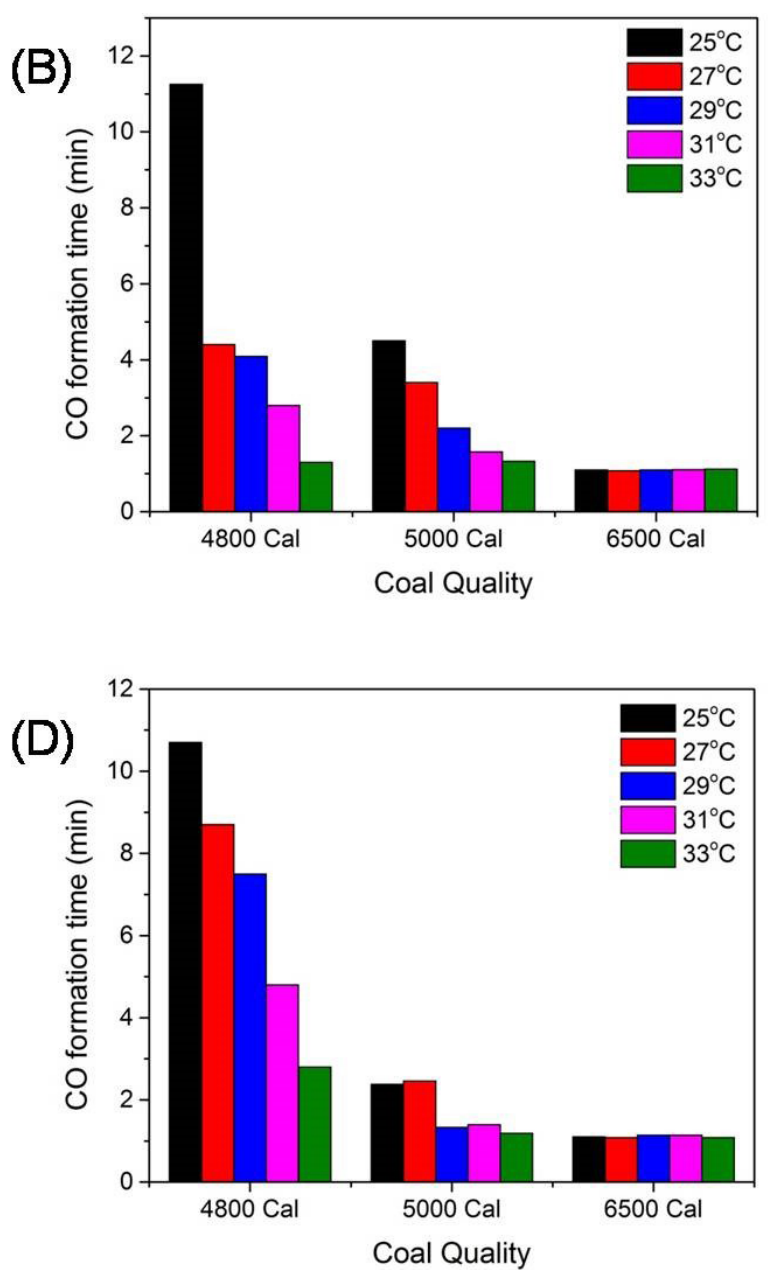

Figure 4. The effect of temperature on the formation of carbon monoxidee:

(A) at $250 \mathrm{~g}$; (B) $500 \mathrm{~g}$; (C) $750 \mathrm{~g}$; and (D) $1000 \mathrm{~g}$

\section{The effect of airflow on the CO formation time}

The further study is conducted to investigate the effect of airflow concentration on the $\mathrm{CO}$ formation. Figure 5(A) showed that the $5 \mathrm{sccm}$ airflow boost the $\mathrm{CO}$ formation time from approximately 11.2 minutes in $1 \mathrm{sccm}$ of airflow to $3 \mathrm{~min}$ utes in 4800 calories coal sample. Moreover, the other coal sample also provides the similar result where the increase of airflow provide a shorter $\mathrm{CO}$ formation time. Therefore, even $5 \mathrm{sccm}$ provide the highest coal oxidation, flowing $3 \mathrm{sccm}$ of air into the reactor slashed approximately $50 \%$ of $\mathrm{CO}$ formation time compared to the one in $1 \mathrm{sccm}$ of airflow injecting to the reactor.

The effect of temperature and airflow are further conducted to see the combination performance of temperature and airflow effects. Figure 5B-5E shows that all the coal sample definitely decrease the $\mathrm{CO}$ formation time by increase the temperature, indicating the temperature and airflow provide the positive effects to coal oxidation. The airflow provide the heat distribution in all coal surface, resulting in a higher coal oxidation. However, increasing the temperature above $29^{\circ} \mathrm{C}$ boost $50 \%$ of coal oxidation indicated by the CO formation time which $\sim 50 \%$ shorter compared to the $\mathrm{CO}$ formation time at $29^{\circ} \mathrm{C}$ in all coal calorific sample. The result is in accordance with the result of previous study which showed that the temperature above $29^{\circ} \mathrm{C}$ greatly improved the $\mathrm{CO}$ formation time. Furthermore, Figure $5 \mathrm{~B}-5 \mathrm{E}$ presents that the airflow just significantly affect the $\mathrm{CO}$ formation time in the lower temperature (less than $29^{\circ} \mathrm{C}$ ), where in the temperature above $29^{\circ} \mathrm{C}$, the airflow effect do not significantly increase the coal oxidation. The result proved that temperature played the main role in improving coal oxidation than airflow effects. Nevertheless, airflow parameter still provide the improvement and can not be negligible. 

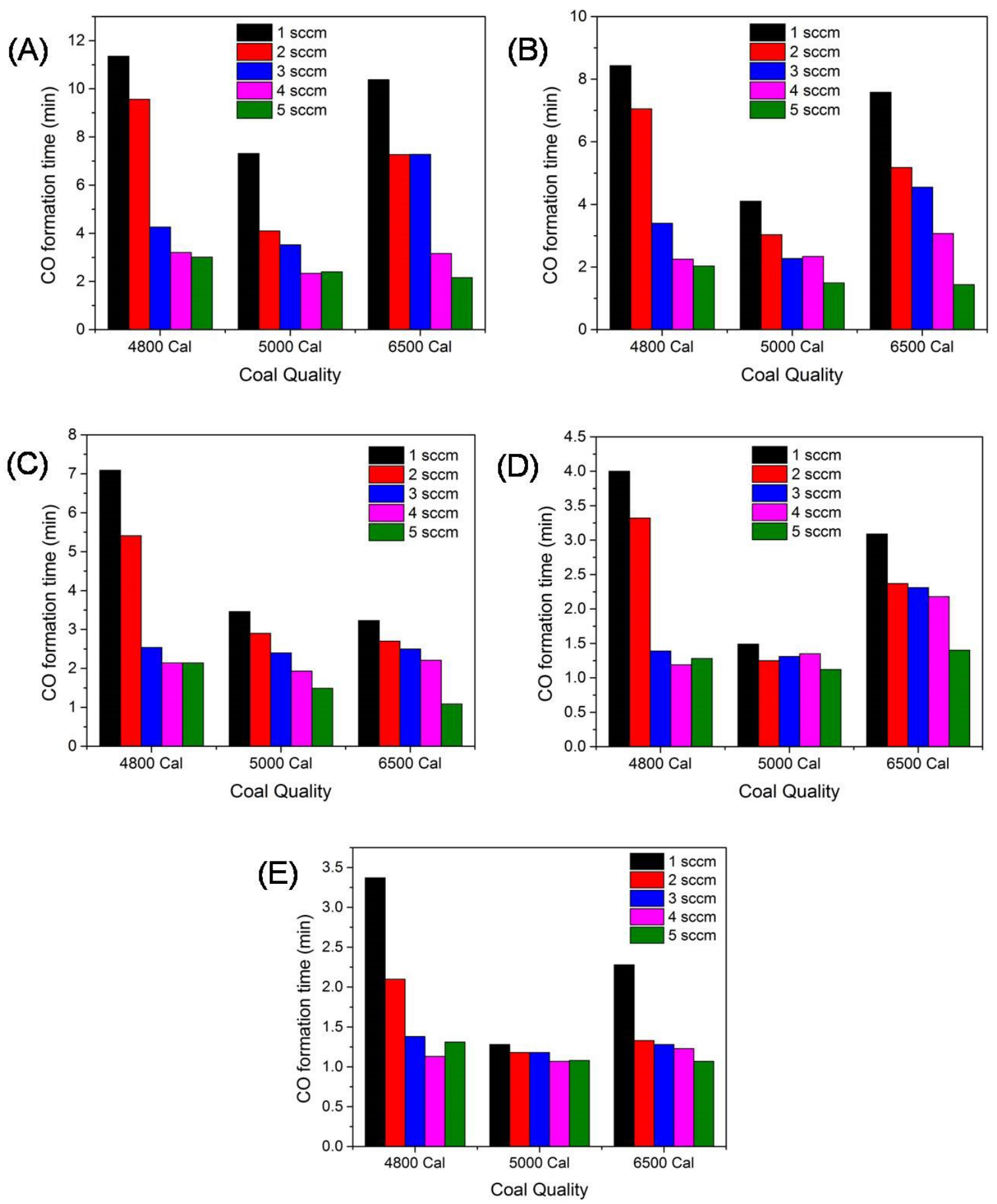

Figure 5. The effect of air flow concentration ( $\mathrm{sccm}$ ) in the formation of carbon monoxide. The experiment was carried out in 250 gram of coal sample under several temperatures;

(A) $25^{\circ} \mathrm{C}$; (B) $27^{\circ} \mathrm{C}$; (C) $29^{\circ} \mathrm{C}$; (D) $31^{\circ} \mathrm{C}$; and (E) $33^{\circ} \mathrm{C}$

\section{CONCLUSION}

In conclusion, the present study found that the carbon monoxide occurred as the product of coal oxidation and the $\mathrm{CO}$ formation is differentiated by coal quality and coal weight. Furthermore, several parameters including ambient temperature, and airflow provide a significant effect to boost the $\mathrm{CO}$ formation time. To be more specific, the ambient temperature become the important parameter in the boosting of $\mathrm{CO}$ formation time where airflow only enhance the $\mathrm{CO}$ formation time in low temperature condition (below $29^{\circ} \mathrm{C}$ ). Finally, all of these finding information become the valuable information in the coal activities management especially in determining the further action to prevent the spontaneous coal combustion in coal mining activities. 


\section{Acknowledgements}

Authors thank PT. Bukit Asam, Tbk for providing the coal sample and support this study. Authors acknowledge the South Sumatera Provincial Head of Energy and Mineral Source Department of the Ministry of Energy and Mineral Source of Republic of Indonesia.

\section{REFERENCES}

1. American Society for Testing and Materials. 2004. Standard Classification of Coals by Rank, ASTM D 388-399. Philadelphia

2. Artiola J.F., Walworth J.L., Musilm S.A., Crimmins A. 2019. Soil and Land Pollution. Environmental and Pollution Science (3rd Edition), pp. 219-235.

3. Beamish B.B., Hamilton G.R. 2005. Effect of moisture content on the R70 self-heating rate of Callide coal. International Journal of Coal Geology 64, 133-138.

4. Beamish B.B., Schultz T.J. 2008. Moisture Content Impact on the Self-Heating Rate of a Highly Reactive Subbituminous Coal. Coal Operators' Conference, University of Wollongong \& the Australasian Institute of Mining and Metallurgy, 155-160.

5. Bhat S., Agarwal P.K. 1996. The effect of moisture condensation on the spontaneous combustibility of coal. Fuel 75, 1523.

6. Day S.J., Riley K.W. 2004. Waste streams in black coal mining and coal-fired power generation. Research Report 42. Pullenvale, Qld, Australia, CCSD (Cooperative Research Centre for Coal in Sustainable Development), CQAT Technology Transfer Centre.

7. Heffern E.L., Coates D.A. 2004. Geologic history of natural coal-bed fires, Powder River Basin, USA. International Journal of Coal Geology 59, 25-47.

8. Huda A., Mahendra I.P., Ichwani R., Handoko C. T., Ngoc H.M., Yudono B., Bustan M.D., Gulo F. High efficient visible-light activated photocatalytic semiconductor $\mathrm{SnO} 2 / \mathrm{Sn} 3 \mathrm{O} 4$ heterostructure in direct blue 71 (DB71) degradation. Rasayan Journal of Chemistry 12, 308-318.
9. Huda A., Suman P.H., Torquato L.D.M., Silva B.M., Handoko C.T., Gulo F., Zanoni M.V.B., Orlandi M.O. 2019. Visible-light driven photoelectrocatalytic degradation of acid yellow 17 using Sn3O4 flower-like thin films supported on Ti substrate (Sn3O4/TiO2/Ti). Journal of Photochemistry and Photobiology A: Chemistry 276, 196-205.

10. Kuenzer C., Stracher G.B. 2012. Geomorphology of coal seam fires. Geomorphology 138, 209-222.

11. Kurniawan I., Nasir S., Hermansyah, Mardiyanto. 2017. The Screening of Potential Antibiotics from Hospital Wastewater in Tropical Region. Pollution Research 36, 343-351.

12. McNeill F.V. 2019. Addressing the Global Air Pollution Crisis: Chemistry's Role. Trends in Chemistry. Vol. 1, pp. 5-8.

13. O’Keefe J.M.K., Neace E.R., Lemley E.W., Hower J.C., Henke K.R., Copley G., Hatch R.S., Satterwhite A.B., Blake D.R. 2011. Old Smokey coal fire, Floyd County, Kentucky: estimates of gaseous emission rates. International Journal of Coal Geology $87,150-156$.

14. Onifade M., Genc B. 2018. Spontaneous combustion of coals and coal shales. International Journal of Mining Science and Technology 28, 933-940.

15. Stracher G.B., Sokol E.V., Prakash A. 2019. Coal and Peat fires: A global perspective. Vol 1, pp. 1-36.

16. United States Environmental Protection Agency. 2018. Source of Greenhouse Gas Emissions.

17. van Dijk P., Zhang J., Jun W., Kuenzer C., Wolf K-H. 2011. Assessment of the contribution of insite combustion of coal to greenhouse gas emission: based on a comparison on Chinese mining information to previous remote sensing estimates. International Journal of Coal Geology 86, 108-119.

18. Wang K., Deng J., Zhang Y., Wang C. 2018. Kinetics and mechanisms of coal oxidation mass gain phenomenon by TG-FTIR and in situ IR analysis. Journal of Thermal Analysis and Calorimetry 132, 591.

19. Wu Y., Yu X., Hu S., Shao H., Liao Q., Fan Y. 2019. Experimental study of the effects of stacking modes on the spontaneous combustion of coal gangue. Process Safety and Environmental Protection 123,39 . 